\title{
Qualitative In Vitro Evaluation of Plant Growth Promoting Activity of Selected Microbial Isolates Used for Biofertilizer Application
}

\author{
Marwanto $^{1 *}$, Hendri Bustaman ${ }^{2}$, Merakati Handajaningsih ${ }^{1}$, Supanjani ${ }^{1}$, Bambang \\ Gonggo Murcitro ${ }^{3}$
}

\author{
${ }^{1}$ Departement of Agronomy, Faculty of Agriculture, University of Bengkulu, W.R.Supratman, st. Kandang Limun, \\ Bengkulu, 38371. \\ ${ }^{2}$ Departement of Plant Prtection, Faculty of Agriculture, University of Bengkulu, W.R.Supratman, st. Kandang Limun, \\ Bengkulu, 38371. \\ ${ }^{3}$ Department of Soil Science, Faculty of Agriculture, University of Bengkulu, W.R.Supratman, st. Kandang Limun, \\ Bengkulu, 38371. \\ *Corresponding author. Email:marwanto@unib.ac.id
}

\begin{abstract}
The use of microbial strains with plant growth promoting (PGP) properties is advisable as a sustainable alternative to chemical fertilizers to improve soil fertility and crop yields. The present study identify 12 specific microbial isolates (7 bacterial and 5 fungal isolates) to have PGP activity viz. atmospheric N fixation, phosphate and potash solubilization, indole acetic acid (IAA) production, and cellulase production. This research work was conducted at the Laboratory of Plant Protection Faculty of Agriculture University of Bengkulu in 2020. The results showed that N fixation ability was observed in Bacillus megatrium, Bacillus sp., Azotobacter sp., and Pseudomomas fluorescent. The highest phosphate solubilization index for bacterial isolate (1.95) was observed in Bacillus sp. and for fungal isolate (1.38) was in Aspergillus niger. The highest potash solubilization index for bacterial isolate (1.86) was observed in $P$. fluorescent andfor fungal isolate (2.06) was in Paeceilomyces sp. IAA production activity was observed in all isolates tested (except for Paeceilomyces sp. and Trichoderma sp.). Cellulase production trait was observed in all isolates tested. The highest cellulase production index was observed in Azotobacter sp. (1.71) for bacteria and Saccharomyces sp. (1.31) for fungi. Thus, the 12 isolates hold promise to be used as a biofertilizer through their potential PGP traits.
\end{abstract}

Keywords: biocontrol cctivity; biofertilizer;indole acetic acid;nitrogen fixation; plant growth promoting trait

\section{INTRODUCTION}

The low availability of soil nutrients required for plant growth especially nitrogen $(\mathrm{N})$, phosphorus $(\mathrm{P})$, and potassium $(\mathrm{K})$ leads to low yields. The use of chemical fertilizers is one tool for raising plant yields and available plant nutrients. Chemical fertilizers may provide important macro nutrients, such as $\mathrm{N}, \mathrm{P}$, and $\mathrm{K}$, and micro nutrients, such as copper $(\mathrm{Cu})$ and iron $(\mathrm{Fe})$. Chemical $\mathrm{N}$ fertilizers are essential to crop yields and are widely used in agricultural systems; however, their use also has some adverse environmental effects. They are vulnerable to leaching, denitrification and volatilization. All of the $\mathrm{N}$ fertilizers have the potential to be particularly toxic to humans[1].

Phosphorus can only be found in two types, $\mathrm{H}_{2} \mathrm{PO}_{4}$ and $\mathrm{HPO}_{4}{ }^{=}$. As phosphate fertilizer is applied to the soil, it can be quickly immobilized and made unavailable to plants. Most agricultural soils have large phosphorus reserves, many of which have accumulated as a result of repeated use of $\mathrm{P}$ fertilizers. However, a large amount of soluble inorganic phosphate applied to soil as chemical fertilizers is instantly immobilized after application and becomes inaccessible to plants as a result of phosphate fixation and precipitation by aluminum, calcium, iron, magnesium, soil type and soil $\mathrm{pH}$. In acid soil, phosphorus is tightly fixed by aluminum and iron free oxides and hydroxides, resulting in a low efficiency of soluble $\mathrm{P}$ fertilizers such as super calcium phosphate [2].Potassium is the third most essential crop nutrient after nitrogen and phosphorus. It is important for agriculture to promote early growth, boost protein production, water retention, yield, nutritional value, color, texture, and disease resistance of food crops [3].

There are also advantages from the use of chemical fertilizers. They function instantly and provide all the necessary nutrients that are ready to be used. In addition, they are relatively inexpensive and easy to buy and use. 
However, in addition to the exponential growth of the world's population and the huge increase in the usage of chemical fertilizers, environmental issues such as leaching, runoff, deforestation and eutrophication of rivers have become critical due to the low absorption rate of chemical fertilizers by plants, which are only about $50 \%$. Chemical fertilization can also build up toxic waste in soil and decrease the enzyme activity of soil microbes, soil $\mathrm{pH}$ and soil structure[4]. With regards the price, chemical fertilizers are costly for many of the world's farmers who rely on organic matter as a nutrient source in subsistence agriculture. Problems related to NPK chemical fertilizers urge the need to develop cost - effective and environmentally safe fertilizers to substitute or partially replace chemical fertilizers.

It has been shown that the use of beneficial living microorganisms as an alternative tool to enhance nutrient uptake, stimulate plant growth and increase yield has been beneficial. As a consequence of that, there is a growing incentive for the use of beneficial living microorganisms as biofertilizers [5].

Biofertilizers are, by definition, substances that contain living microorganisms that, when applied to seeds, plant surfaces or soils, colonize the rhizosphere or the interior of the plant and promote growth by increasing the supply or availability of primary nutrients to the host plant.The living microorganisms, including rhizospheric fungi, rhizospheric bacteria, symbiotic bacteria and nonsymbiotic endophytic bacteria, have the capacity to stimulate plant growth by supporting plant nutrient status. Rhizospheric fungi, including arbuscular mycorrhiza and Penicillium bilaii are acknowledged to have growthenhancing capabilities[5].

Nitrogen-fixing bacteria include symbiotic (Rhizobium) and free-living bacteria (Pseudomonas spp., Bacillus spp., Azospirillum spp., and Burkholderia spp.). These have also been known as plant growth enhancers [6]. Free-living, N-fixing bacteria are Azospirulum, Azotobacter, and Pseudomonas. These bacteria are able to fix atmospheric nitrogen without a specific host plant compared to Rhizobium legume.These free-living N-fixing bacteria replicate in plants and successfully settle in roots, stems and leaves as colony. During this association, the invasive bacteria rewarded the hosts acquired with substantial improvements in plant growth, vigor and yield [7]. Azoarcus sp., Gluconacetobacter diazotrophicus, Herbaspirilium sp.,Azoarcus sp., Gluconacetobacter diazotrophicus, Herbaspirillium sp., Azotobacter sp., Acetobacter, Azospirillum, Azomonas, Bacillus, Beijerinckia, Clostridium, Enterobacter, Klebsiella, Pseudomonas, and Xanthobacter are major N-binding bacteria [8] [9].The synthesis and secretion of plant growth regulators such as auxins, cytokines, gibberellins and nitric oxides are essential signals and components of plant growth promotion effects [10].

Pseudomonas, Bacillus, Rhizobium, Burkholderia, and Erwinia have been shown to have phosphate- solubilizing activity. These microorganisms are able to convert insoluble inorganic phosphate compounds, such as tricalcium phosphate, dicalcium phosphate, hydroxyapatite, and rock phosphate, into usable plant forms [11]. The application of phosphate-solubilizing bacteria (PSB) provides an increase in maize yields and decreases the need for phosphate fertilizers [12].

Many fungal species can solubilize rock phosphate, aluminum phosphate and tricalcium phosphate, such as Aspergillus niger, Aspergillus tubingensis, Aspergillus fumigatus, Aspergillus terreus, Aspergillus awamor, Penicillium italicum, Penicillium radicum, Penicillium rugulosum, Fusarium oxysporum, Curvularia lunata, Humicola sp., Sclerotium rolfsii, Pythium sp., Aerothecium sp., Phoma sp., Cladosporium sp, Rhizoctonia sp., Rhizoctonia solani, Cunninghamella spp., Rhodotorula sp., Candida sp., Schwanniomyces occidentalis, Oideodendron sp., Pseudonymnoascus sp. [13] [14] [15].

Potassium-solubilizing bacteria (KSB) are capable of liquifying non-available potassium in accessible forms through organic acid secretion[5]. Bacillus mucilaginosus has been intensively studied as a biofertilizer among these bacteria. Other genera such as Burkholderia sp., Paenibactillus sp., and Acidothiobacillus sp. are also reported as KSB [16]. KSBs have the ability to solubilize plant non-accessible potassium into plant-available forms by organic acid release. KSB is a heterotrophic bacterium that can produce energy and cellular carbon from preexisting organic materials. KSB also plays a vital role in maintaining the soil structure and helping to conserve soil water.

Indole acetic acid (IAA) is one of the most physiologically active auxins. IAA is a natural product of L-tryptophan metabolism generated by a variety of microorganisms, such as Plant Growth-Promoting Rhizobacteria (PGPR)[17].Bacteria that colonize the rhizosphere and plant roots and promote plant growth by any process is called PGPR. PGPR can demonstrate a variety of characteristics responsible for affecting plant growth. The ordinary traits encompass the development of plant growth regulators (such as auxin, gibberellin, ethylene), siderophores, $\mathrm{HCN}$, and antibiotics [6].Bacteria produce auxins to disrupt host physiological processes for their own benefit. The microorganisms isolated from different crop regions of the rhizosphere have the potential to generate IAA as secondary metabolites due to the rich supply of substrates.IAA promotes longer root growth with an increased number of root hairs and root laterals responsible for the uptake of nutrients [18].IAA promotes cell elongation by altering certain factors such as increasing the osmotic content of the cell, increasing the permeability of water to the cell, decreasing the pressure of the wall, increasing the synthesis of the cell wall, and inducing particular RXA and protein synthesis.It encourages embryonic development, prevents or slows down the abscission of leaves, and stimulates flowering and fruiting[19]. 
IAA is a metabolite produced from Trp by several Trp-dependent and Trp-dependent pathways in plants and bacteria. More than one pathway may be exist in the bacteria. Physiological evidence has been documented for various Trp-dependent synthesis pathways in Azospirillum brasilense [20].In the Trp-dependent pathway, tryptophan is transformed into indole-3-acetamide (IAM) by tryptophan-2-monooxigenase and IAM is assimilated to IAA by IAM-hydrolase. Horemans and Vlassak [21] have shown that Azospirillum. brasilense may have developed IAA in the void of tryptophan under aerobic growth. Some microorganisms produce auxins in the presence of a suitable precursor such as L-tryptophan. The tryptophan increases the production of IAA in Bacillus amyloliquefaciens FZB42. Karnwal [22] tested fluorescent Pseudomonas isolates for their ability to produce indole acetic acid in pure culture in the absence and presence of L-tryptophan and found that for both strains, indole production enhanced with increases in tryptophan concentration.

Restu and Payangan [23] reported that five fungus genera (Aspergillus, Trichoderma, Rhizopus, Penicillium, and Fusarium) had ability to produce IAA. Among these fungus, Fusarium has the highest concentration, which was $38,611 \mathrm{ppm}$. Fusarium isolates have the potency to be developed as biological fertilizers.

It has shown that the highest levels of auxin were developed in the existence of NH4.It plays significant roles during embryogenesis when fine regulation of low levels of IAA is essential to polar development. Trpindependent pathways can make a major contribution to the newly synthesized IAA; however, comprehensive Trpto-IAA conversion occurs in these preparations as well[6].

In addition to exhibiting PGP traits, certaian PGP microorganisms have the ability to produce hydrolytic enzymes suc as cellulase. These enzymes contribute to the destruction of pathogenic microbes cell wall and degradation of lignocellulotic waste. PGP microrganisms producing this lytic enzme have been proven to demonstrate biocontrol properties against a wide range of pathogenic bacteria and fungi and ultimately increase crop yield [24].The degradation of lignocellulose is mainly accomplished by producing two types of extracellular enzyme systems: hydrolytic and oxidative catalytic systems. Microorganism responsible for the degradation of lignocellulose include species of bacteria (for example; Clostridium, Cellulomonas, Bacillus, Pseudomonas, Fibribacter, Ruminococcus, Butyrivibrio) and fungi (for example: Aspergillus, Rhizopus, Trichoderma, Fusarium, Neurospora, Penicillium). Of them, fungi are the principal agents involved in the degradation of lignocelluloses. Efficient cellulolytic fungi are represented by the species of Aspergillus,Penicillium, Chaetomium, Trichoderma, Fusarium, Stachybotrys, Cladosporium, Alternaria, Acremonium, Ceratocystis, Myrothecium, Humicola[25].

Finding cellulose degrading microbes is very important since they are highly needed in industrial and biotechnological sectors (Kasana et al., 2008). For these concern, the purpose of this study was to characterize the ability of selected microbial isolates to produce ammonia $\left(\mathrm{NH}_{3}\right)$ and plant hormone (IAA), solubilize phosphate (P) and potassium $(\mathrm{K})$ and their biocontrol property checked by cellulase enzyme production ability. Theoretically, isolate having multiple traits have more chance to contribute plant growth promotion effects.

\section{MATERIALS AND METHODS}

\subsection{Microbial Isolate Cultures}

The 12 purified microbial isolates consisting of 7 bacterial and 5 fungal isolates were used in this study as shown in Table 1. The pure isolated colony of each microbial isolate was obtained from personal culture collection after sub-culturing several times on the nutrient agar plate. The 12 pure microbial isolates were screened in vitro for different PGP traits such as $\mathrm{N}$ fixation indicated by ammonia $\left(\mathrm{NH}_{3}\right)$ production, phosphate $(\mathrm{P})$ and potash (K) solubilization, IAA production, and biocontrol property by checking cellulase enzyme production ability.

\subsection{In Vitro Characterization of Plant Growth- Promoting Traits of the Isolates}

\subsubsection{Test for Nitrogen Fixation Activity}

Microbial ability in fixing atmospheric $\mathrm{N}$ asymbiotically.Ammonia production indicated by ammonia production of each isolate was tested and performed according to Dobereiner method (Dobereiner, 1995) using a semisolid medium of $\mathrm{Nfb}$ (nitrogen-free bromthymol blue) without $\mathrm{N}$. The $\mathrm{Nfb}$ contained $\left(\mathrm{g} \mathrm{L}^{-1}\right)$ : malic acid, 5.0; $\mathrm{K}_{2} \mathrm{HPO}_{4}, 0.5 ; \mathrm{MgSO}_{4} .7 \mathrm{H}_{2} \mathrm{O}, 0.2 ; \mathrm{NaCl}$, $0.1 ; \mathrm{CaCl}_{2} . \quad 2 \mathrm{H}_{2} \mathrm{O}, \quad 0.02 ; \quad$ micronutrient solution $\left(\mathrm{CuSO}_{4} 5 \mathrm{H}_{2} \mathrm{O}, 0.04 ; \mathrm{ZnSO}_{4} 7 \mathrm{H}_{2} \mathrm{O}, 0.12 ; \mathrm{H}_{3} \mathrm{BO}_{3}, 1.40\right.$; $\mathrm{Na}_{2} \mathrm{MoO}_{4} 2 \mathrm{H}_{2} \mathrm{O}, 1.0 ; \mathrm{MnSO}_{4} \mathrm{H}_{2} \mathrm{O}, 1.175$ ); bromothymol blue, $2 \mathrm{~mL}\left(5 \mathrm{~g} \mathrm{~L}^{-1}\right.$ in $\left.0.2 \mathrm{~N} \mathrm{KOH}\right)$ as an indicator; FeEDTA (solution $16.4 \mathrm{~g} \mathrm{~L}^{-1}$ ), $4 \mathrm{~mL}$; vitamin solution (biotin, $10 \mathrm{mg}$ ); pyridoxal- $\mathrm{HCl}, 20 \mathrm{mg}$; $\mathrm{KOH}, 4.5 \mathrm{~g}$. A quantity of 1.6 to $1.80 \mathrm{~g}$ agar $\mathrm{L}^{-1}$ was added to prepare the semi-solid medium. Distilled water was added to bring the final volume to $1,000 \mathrm{~mL}$ and adjust $\mathrm{pH}$ to 6.5. Each isolate was inoculated and grown into test tubes containing the $\mathrm{NFb}$ and incubated at room temperature $\left(30^{\circ} \mathrm{C}\right)$ for $5-7$ days. The strains that show a veil-like pellicle ring structure beneath the surface of the media were assumed as successful ammonia production or the microorganism had putative nitrogen-fixing activity. Observation of the initial pellicle formation was conducted 2-3 days after inoculation and growth was then observed every subsequent day as some bacteria and fungi could grow very quickly. Three replicate plates were used for each isolate.

\subsubsection{Test for Phosphate Solubilization Activity}

The ability of the 12 microbial isolates to solubilize insoluble $\mathrm{P}$ was identified using the plate method [26] 
using Pikovskaya (PVK) agar medium containing $\mathrm{KH}_{3}(\mathrm{PO} 4)_{2}$ as an insoluble inorganic form of $\mathrm{P}$ source. The appearances of the clear zone around bacterial or fungal growth (phosphate solubilization zone) were indicated a positive result for phosphate solubilization [27]. The Pikovskaya agar medium contained $10 \mathrm{~g}$ glucose; $5 \mathrm{~g}\left[\mathrm{KH}_{3}\left(\mathrm{PO}_{4}\right)_{2}\right] ; 0.5 \mathrm{~g}\left(\mathrm{NH}_{4}\right)_{2} \mathrm{SO}_{4} ; 0.2 \mathrm{~g} \mathrm{KCl}$; $0.1 \mathrm{MgSO}_{4} \cdot 7 \mathrm{H}_{2} \mathrm{O}$; small amount of $\mathrm{MnSO}_{4}$ and $\mathrm{FeSO}_{4}$; $0.5 \mathrm{~g}$ of yeast extract, $15 \mathrm{~g}$ of bacto agar. Distilled water was added to bring the final volume to $1,000 \mathrm{~mL}$ and adjust $\mathrm{pH}$ to 6.5 . Each isolate was spot inoculated by streaking in the solid PVK medium in a petri dish using ose needle and incubated at $28^{\circ} \mathrm{C}$ for seven days. Bacterial or fungal colonies surrounded by a clear halo zone, indicating phosphate removal, were visually observed and measured. The solubilization index was measured according to the ratio of total diameter (the sum of colony diameter and the halo zone diameter and the colony diameter [28] Three replicate plates were used for each isolate.

\subsubsection{Test for Potash Solubilization Activity}

A total of 12 microbial isolates were tested for potassium solubilizing activity on Aleksandrov agar medium having: $0.5 \%$ glucose, $0.05 \%$ magnesium sulfate heptahydrate, $0.0005 \%$ iron chloride, $0.01 \%$ calcium carbonate, $0.2 \%$ calcium phosphate, $0.2 \%$ feldspar (potassium aluminum silicate) and $1.8 \%$ agar; by spot plate method. Distilled water was added to bring the final volume to $1,000 \mathrm{~mL}$ and adjust $\mathrm{pH}$ to 6.5 . Each isolate was spot inoculated by streaking in the solid Aleksandrov agar medium in a petri dish using ose needle and incubated at $28^{\circ} \mathrm{C}$ for seven days. Appearance of a clear halo zone developed around each colony after 5 days incubation indicated potash solubilization. The halo size produced by the respective strain was measured to calculate $\mathrm{K}$ solubilization index. The solubilization index was measured according to the ratio of total diameter (the sum of colony diameter and the halo zone diameter and the colony diameter [28]. All the observations were recorded in triplicate.

\subsubsection{Test for IAA Production}

IAA production was detected on Luria-Bertani agar medium (LB) containing the following (in grams per liter): Bacto-Tryptone (Difco), 10; yeast extract, 5; NaCl, 5; and Bacto-agar (Difco) [29]. The LB medium was added with $5 \mathrm{mM}$ L-tryptophan the precursor of IAA. Distilled water was added to bring the final volume to $1,000 \mathrm{~mL}$ The $\mathrm{pH}$ was adjusted to 7.5 with $1 \mathrm{~N} \mathrm{NaOH}$ before autoclaving. Each isolate was individually spot inoculated by streaking on the plates of LB medium in a petri dish using ose needle. Each inoculated plate was overlaid with an 82mm-diameter disk of Whatman paper. All plates were incubated until colonies reached 0.5 to $2 \mathrm{~mm}$ in diameter. After an appropriate incubation period, the paper was removed from the plate and saturated with Salkowski reagent. The reagent was prepared by mixing $50 \mathrm{ml} \mathrm{35 \%}$ of $\mathrm{HClO}_{4}$ with $1 \mathrm{ml} 0.5 \mathrm{M} \mathrm{FeCl}_{3}$ solution [30]. Membranes were saturated in a petri dish by soaking directly in $4.0 \mathrm{ml}$ the Salkowski reagent and incubated for $0.5-2$ hours for color development. The reaction was allowed to proceed until adequate color developed. All reagent incubations were conducted at room temperature. Bacteria or fungi producing IAA were characterized by the appearances of a specific red halo within the membrane immediately surrounding the colony, indicating a positive result for IAA production. All the observations were recorded in triplicate.

\subsubsection{Test for Cellulase Production}

The 12 microbial isolates were confirmed for the ability to produce cellulose enzyme on a medium containing low viscosity carboxymethyl cellulose (CMC) agar as the sole carbon source. The composition of the CMC solid agar was as follows: $\mathrm{NaNO}_{3}\left(3.0 \mathrm{~g} \cdot \mathrm{L}^{-1}\right)$; $\mathrm{K}_{2} \mathrm{HPO}_{4}\left(1.0 \mathrm{~g} \cdot \mathrm{L}^{-1}\right) ; \mathrm{MgSO}_{4}\left(0.5 \mathrm{~g} \cdot \mathrm{L}^{-1}\right) ; \mathrm{KCl}\left(0.5 \mathrm{~g} \cdot \mathrm{L}^{-1}\right)$; $\mathrm{FeSO}_{4} \cdot 7 \mathrm{H}_{2} \mathrm{O}\left(0.01 \mathrm{mg} \cdot \mathrm{L}^{-1}\right)$; agar $\left(20.0 \mathrm{~g} \cdot \mathrm{L}^{-1}\right)$; CMC $(15.0$ $\mathrm{g} \cdot \mathrm{L}^{-1}$ ) [31] Distilled water was added to bring the final volume to $1,000 \mathrm{~mL}$. The $\mathrm{pH}$ was adjusted to 6.5 prior to sterilization. Each isolate was individually spot inoculated by streaking on the plates of CMC agar in a petri dish using ose needle and incubated at $37{ }^{\circ} \mathrm{C}$ for 72 hours. After incubation, CMC agar plates were flooded with $0.1 \%(\mathrm{w} / \mathrm{v})$ Congo red reagent and allowed to stand for 15 min. at room temperature, then washed with $1 \mathrm{M} \mathrm{NaCl}$ [32] (Ten et al., 2004). The formation of a clear pale halo zone with orange edge circling around each microbial colony indicated an area of cellulose hydrolysis by cellulase enzyme. This halo area was measured for subsequent calculation of the enzymatic index (EI) The EI was measured according to the ratio of total diameter (the sum of colony diameter and the halo zone diameter and the colony diameter [33]. The strains that showed an EI higher than 1.50 were considered to be potential producers of cellulases. For each strain the average EI of the three replicates was calculated.

\subsection{Methods of Data Analysis}

Data analysis was carried out using figure, table, and percentiles to evaluate PGP traits and biocontrol property of cultivable potential plant growth promoting microbial isolates. 
Table 1 Multiple plant prowth promoting properties of selected microbial isolates.

\begin{tabular}{|c|c|c|c|c|c|c|c|c|}
\hline $\begin{array}{l}\text { Isolate } \\
\text { Code }\end{array}$ & $\begin{array}{c}\mathrm{N} \\
\text { Fixation }\end{array}$ & $\begin{array}{c}\mathrm{P} \\
\text { Solubilization }\end{array}$ & PSI & $\begin{array}{c}\mathrm{K} \\
\text { Solubilization }\end{array}$ & KSI & $\begin{array}{c}\text { IAA } \\
\text { Production }\end{array}$ & $\begin{array}{l}\text { Cellulase } \\
\text { Production }\end{array}$ & EI \\
\hline $\mathrm{BI}_{1}$ & + & + & 1.46 & + & 1.52 & + & + & 1.35 \\
\hline $\mathrm{BI}_{2}$ & + & - & - & - & - & + & + & 1.71 \\
\hline $\mathrm{BI}_{3}$ & + & + & 1.95 & + & 1.63 & + & + & 1.63 \\
\hline $\mathrm{BI}_{4}$ & + & + & 1.41 & + & 1.86 & + & + & 1.53 \\
\hline $\mathrm{BI}_{5}$ & + & + & 1.30 & - & - & + & + & 1.18 \\
\hline $\mathrm{BI}_{6}$ & - & - & - & - & - & + & + & 1.59 \\
\hline $\mathrm{BI}_{7}$ & - & - & - & - & - & + & + & 1.34 \\
\hline $\mathrm{FI}_{1}$ & - & + & 1.32 & + & 2.06 & & + & 1.26 \\
\hline $\mathrm{FI}_{2}$ & - & + & 1.38 & + & 1.28 & + & + & 1.08 \\
\hline $\mathrm{FI}_{3}$ & - & - & - & + & 1.25 & + & + & 1.08 \\
\hline $\mathrm{FI}_{4}$ & - & - & - & - & - & + & + & 1.31 \\
\hline $\mathrm{FI}_{5}$ & - & + & - & + & 1.80 & + & + & 1.08 \\
\hline
\end{tabular}

\section{Remarks:}

$+=$ activity detected

$\mathrm{BI}_{1}=$ Bacillus megatrium

$\mathrm{BI}_{2}=$ Azotobacter $\mathrm{sp}$.

$\mathrm{BI}_{3}=$ Bacillus sp.

$\mathrm{BI}_{4}=$ Pseudomonas flurescent

$\mathrm{BI}_{5}=$ Chromobacterium $\mathrm{sp}$.

$\mathrm{BI}_{6}$

$\mathrm{BI}_{7}$

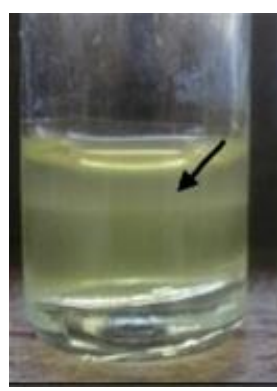

(a)

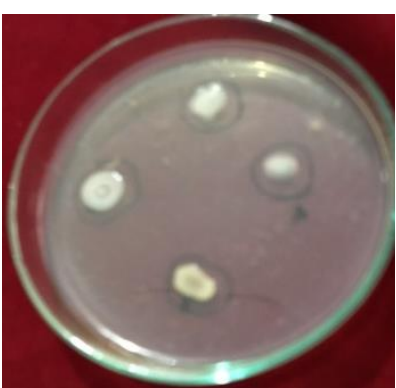

(b)

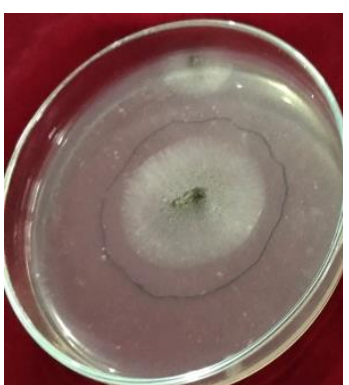

(c)

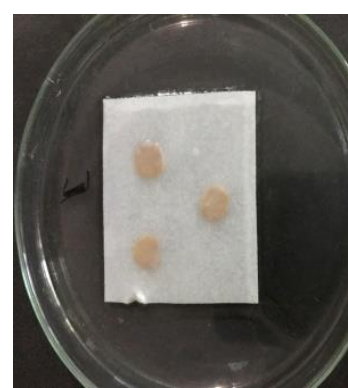

(d)

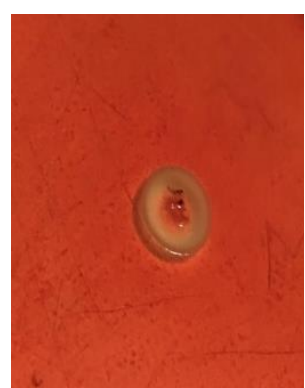

(e)

Figure 1: (a) N fixation (pellicle formation indicated by an arrow); (b) phosphate (P) solubilization (indicated by a clear halo zone around isolate colony; (c) potash $(\mathrm{K})$ solubilization (indicated by a clear halo zone); (d) IAA production (indicated by pink color formation); (e) cellulase enzyme production (indicated by clear halo zone around isolate colony). 


\section{RESULTS AND DISCUSSION}

\subsection{Nitrogen Fixation}

The present research work used 12 different PGP isolates consisting of 7 bacterial strains and 5 fungal strains as shown in Table 1. Six out of seven bacteria isolates grew well on $\mathrm{N}$-free agar media and produced ammonia after five days incubation at approximately $28^{\circ} \mathrm{C}$ as indicated by appearance of clear pellicle ring structure near the surface of the media (Fig. 1a). The bacteria were identified asBacillus megatrium, Bacillus sp., Azotobacter sp., Pseudomonasfluorescence, B6, and B7. The formation of this structure confirms the potential for fixing atmospheric N. Similar structure was not found in all fungal isolates, meaning that all fungi considered negative for fixing atmospheric N. Reports on the bacterial ability to fix atmospheric $\mathrm{N}$ such as Pantoea, Serratia, Pseudomonas, Bacillus, Enterobacter, and Burkholderia have been demonstrated by Laranjo et al.[34] ; Xu et al. [35]); Zaheer et al. [36].

\subsection{Phosphate Solubilization}

The microbes ability of phosphate solubilization are indicated by the formation of clear halo zone around their colonies when grown in PVK culture media ammended with $\mathrm{KH}_{3}(\mathrm{PO} 4)_{2}$ as an insoluble inorganic form of $\mathrm{P}$ source. The results of this study showed that 4 out of 7 bacterial isolates and 3 out of 5 of fungal isolates generated clear halo zone around the colonies after 5 to 7 days of incubation, demonstrating the ability of phophorus solubilization (Fig. 1b). Thus, they are potentialphosphorus solubilizers. The putative bacteria was Bacillus megatrium, Bacillus sp., Pseudomonasfluorescence, and Chromobacterium sp. The putative fungi was Paeceilomyces sp., Aspergillus niger, Trichoderma sp., and Aspergillus nodulans. According to Fankem et al. [37], the halo zone is produced due to solubilization of insoluble phosphates mediated through the secretion of organic acid by the isolates in the surrounding medium combined with a reduced $\mathrm{pH}$ medium. Phosphate solubilizing bacteria release organic acids which dissolve phosphate mineral through anion exchange or chelation of $\mathrm{Fe}$ and $\mathrm{Al}$ ions associated with phosphate [38].

The ability of miroorganism to solubilize insoluble phosphate was measured by the solubilization index: the ratio of the total diameter (colony + halo zone) and the colony diameter, after 5 days of inoculation as shown in Fig. 1b[28]. Phosphate solubilization index (PSI) values of the isolates varied from 1.30 to 1.95 for bacteria and from 1.25 to 1.38 for fungi. The PSI average of all isolates was 1.44 (Table 1). The highest PSI (1.95) were found in Bacillus sp. and the lowest PSI (1.30) in Chromobacterium sp. for bacteria. The highest PSI (1.38) was observed in Aspergillus niger and the lowet PSI (1.25) in Aspergillus nodulan for fungi (Table 1). Based on colony diameter and halo zone formation, Bacillus sp. was the most efficient rock phosphate solubilizer on PVK agar plates among rock phosphate-solubilizing bacteria, and Aspergillus niger for fungi. The PSI of the most efficient bacteria was greater than that of the fungi although fungi produce large halo zone compared to bacteria.

The different ability of phosphate solubilization based on SI in the present study occurs due to the varying type, amount, and diffusion rates of diverse organic acids produced by fungal isolates as previously reported by Yadav et al. [39]. Iman [40] reported that the SI of the test phosphate solubilizing fungal strains (Penicillium italicum and Aspergillus niger) were 2.42 and 3.15, respectively. On the contrary, Mahamuni et al. [41] reported that SI for different fungal strains isolated from sugarcane and sugar beet varied from 1.13 to 1.59. Alam et al. [39] also reported that the fungal cultures isolated from maize rhizosphere had SI ranging from 1.53 to 1.80 .

No halo zone formation was detected around the bacterial and fungal isolate colonies during the rock phosphate-solubilization tests performed on PVK solid medium. This can, perhaps, be explained by the low diffusion of the organic acids produced by these microorganisms during their growth or the use of a solubilization process without organics acids.

This qualitative test offered feasibility as it can be used for an initial selection of strains, tests in addition to being simple, rapid and well adapted for screening of a large number of samples. However, further test such as ARA (acetylene reductase assay) is needed for confirmation.

\subsection{Potash Solubilization}

The microbes ability of potash $(\mathrm{K})$ solubilization are indicated by the formation of clear halo zone around their colonies when grown in Aleksandrov culture media ammended with feldspar as an insoluble inorganic source of $\mathrm{K}$. The results of this study showed that 3 out of 7 bacterial isolates and 4 out of 5 of fungal isolates generated clear halo zone around the colonies after 5 to 7 days of incubation, demonstrating the ability of $\mathrm{K}$ solubilization (Fig. 1c.). Thus, they are potential K solubilizers. According to Premonoet al. [28], the halo zone is produced due to solubilization of insoluble potash mediated through the secretion of organic acid by the isolates in the surrounding medium. These acids convert insoluble $\mathrm{K}$ such as feldspar to the soluble form of $\mathrm{K}$ (soil solution form) with the availability of major plant nutrients [44] (Bahadur et al. 2014). The putative bacteria was Bacillus megatrium, Bacillus sp., Pseudomonasfluorescence andthe putative fungi was Paeceilomyces sp., Aspergillus niger, Trichoderma sp., and Aspergillus nodulans. Previous works reported that microbes from the genus Aspergillus and Bacillus are efficient K-solubilizers [45].

The ability of the isolate to solubilize insoluble feldspar was measured by the solubilization index: the 
ratio of the total diameter (colony + halo zone) and the colony diameter after 5 days of inoculation, as shown in Fig. 1c. Potash solubilization index (KSI) values varied from 1.52 to 1.83 for bacteria and varied from 1.25 to 2.06 for fungi. The KSI average of all isolates was 1.63 (Table 1). The highest PSI (2.06) were found in Paeceilomyces sp. and the lowest (1.25) in Trichoderma sp. for fungi. KSI value of 1.86 was observed in Pseudomonas fluorescent.

Based on colony diameter and halo zone formation, Paeceilomyces sp. was the most efficient K solubilizer on Aleksandrov agar plates for fungi, and Pseudomonas fluorescent.for bacteria. The KSI of the most efficient fungi was greater than that of the bacteria. The previous research results also evidenced that $\mathrm{K}$ solubilization is done by a wide range of saprophytic bacteria and fungal strains [46], [47].

This test in plates presented feasibility as it can be employed for an initial selection of strains, tests in addition to being simple, rapid and well adapted for screening of a large number of samples.

\subsection{Indole Acetic Acid (IAA) Production}

The presence of bacteria and fungi in rhizosphere contributes to positive impact on plant growth indirectly by playing a role as a biocontrol agent or directly by secreting plant hormone and by assissting resource acquisition (mostly $\mathrm{N}, \mathrm{P}$, and $\mathrm{K}$ ). A lot of attention have been paid on the auxin indole3-acetic acid (IAA) recently. For this concern, 12 isolates were tested for IAA production on the solid Luria-Bertani medium supplemented with tryptophan. When the isolates were inoculated on a nitrocellulose membrane, bacteria or fungi capable of synthesizing IAA exhibits red color on the membrane. The results showed that a concentrated pink color on the membrnae was observed in each bacterial isolate and only 3 out of 5 for fungal isolates tested, indicating that they have the ability to produce IAA (Fig. 1d). The result of this study confirms the results of other scholar. Patten and Glick [48] reported that Tryptophan dependent IAA synthesis had been also determined in several bacteria. Swain et al. [49] have reported IAA producing Bacillus subtilis spp. Auxin production by Bacillus subtilis spp increased when culture medium supplemented with an IAA precursor (tryptophan), which confirm the results of other scholar [50]. In Pseudomonas syringae, IAA biosynthesis occurs mostly from tryptophan via indole-3 acitamide [51] and in Pseudomonas fluorescens, tryptophan bypassing the indole 3actaldehyde, which is further converted into IAA [52].

The two fungal isolates viz. Paeceilomyces sp. and Trichoderma sp. did not develop a pink color formation on the membrane after saturated with Salkwoski reagent, indicating negative IAA formation. These fungus do not have the ability to covert tryptophan into IAA. On the contrary, the other fungus viz. A. niger, A. nodulan, and Saccarhomyces sp. were considered as IAA producer, which partly confirm the results reported by Restu and Payangan [23].They reported that fungus genera
Aspergillus, Trichoderma, Rhizopus, Penicillium, and Fusarium exhibited IAA production ability.

This test in plates offered feasibility as it can be utilized for an early selection of strains, tests in addition to being simple, rapid and well adapted for screening of a large number of samples.

\subsection{Cellulase Production Activity}

This test is based on the observation of the halo zone produced by hydrolysis of cellulose (CMC) by cellulase secreted by bacteria or fungi strains examined. The halo zone produced by hydrolysis of cellulose is directly related to the region of action of the cellulolytic enzymes, since the dye only remains attached to regions where there are $\beta 1,4-\mathrm{D}$-glucanohydrolase bonds. The results of the present study showed that the pale halo zone around the colonies (Fig. 1e), which corresponds to the zone of CMC degradation, was observed in all 12 isolates (equivalent to $100 \%$ of the strains evaluated). Clear halo zones surrounding microbial growing colonies after incubating them for a suitable period confirm their ability for cellulases production [53]. These enzymes are produced by various fungus such as Aspergillus, Cladosporium, Fusarium, Penicillium and Trichoderma species [54]. Azzaz et al. [54] fyrther stated that Aspergillus niger produces highly active cellulase when grown in liquid media by both surface and submerged culture methods and recently by solid state fermentation. Production of cellulase also reported by using substrates like cellulose, xylose and lactose using $T$. reesei[55]. Saravanan et al. [56] studied the production of cellulose using Trichoderma reesei in solid state fermentation. Some species of Penicillium i.e. Penicillium iriensis and $P$. citriviride produce significant quantities of cellulase, when grown under different conditions. Their enzyme activity was confirmed by Congo Red plate screening assay. It was found that Aspergillus niger showed the highest cellulase activity when compared with Trichoderma viride and Bacillus subtilis.

The ability of the isolate to degrade cellulose was measured by the solubilization index: the ratio of the total diameter (colony + halo zone) and the colony diameter after 5 days of inoculation, as shown in Fig.1e. The results showed that he enzyme index (EI) values varied from 1.18 to 1.71 for bacteria and varied from 1.08 to 1.31 for fungi. The EI average of all isolates was 1.353 (Table 1). The highest PSI (1.71) was observed in Azotobacter sp. for bacteria and the lowest (1.08) in A. niger, A. nodulan, and Trichoderma $\mathrm{sp}$. for fungi. Based on the colony diameter and halo zone formation, Azotobacter sp.. was the most efficient amorphous cellulose (CMC) degrader through Congo red tes for bacteria, and Saccarhomyces sp. for fungi. The EI of the most efficient bacteria was greater than that of the fungi. The previous research results also evidenced that cellulase is produced by a wide range of microorganism such as fungi and bacteria [54], [57]. Cellulase is the common enzyme degrading cellulose. Endo-bglucanase, Exo-b-glucanase and b-glucosidase are 
three main components comprising in cellulase enzyme which have been shown to act synergistically in the hydrolysis of cellulose to glucose [58].

According to Ten et al. [59] the diameter of the halo zone is useful for selection of strains that can efficiently degrade polysaccharides such as cellulose. Moreover, the enzymatic index can be used as a simple and rapid methodology to select strains within the same genus that have potential for the production of [60]. Table 1 shows the EI results obtained for cultivation of the fungi in synthetic medium containing $\mathrm{CMC}$ as sole carbon source, after 4 days of incubation at $30^{\circ} \mathrm{C}$. This test in plates presented feasibility as it can be employed for an initial selection of strains, tests in addition to being simple, rapid and well adapted for screening of a large number of samples.

\section{CONCLUSION}

The qualitative assessment by testing in plates with different medium and assay procedures showed that these applied tests were feasible for confirming the multiple ability of the 12 isolates to have PGP properties viz. atmospheric $\mathrm{N}$ fixation, phosphate and potash solubilization, indole acetic acid (IAA) production, and cellulase production.These methods in plates offered feasibility as they can be utilized for an initial selection of strains in addition to being simple, rapid and well adapted for identifying of a large number of samples. The 12 isolates tested exhibit multiple plant growth promoting properties. Hence, these strains can be further formulated into biofertilizer through co-culturing and then applicated for greenhouse and field experiments.

\section{ACKNOWLEDGMENT}

This work was supported by Penelitian Unggulan Universitas Bengkulu Tahun 2020 No. 2000/UN30.15/PG/2020 for the research, authorship, and/or publication of this article. The authors greatly acknowledge the financial support.

\section{REFERENCES}

[1] A. Sanz-Cobeña, L. Sánchez-Martín, L. GarcíaTorres, and A. Vallejo, 'Gaseous emissions of $\mathrm{N}_{2} \mathrm{O}$ and $\mathrm{NO}$ and $\mathrm{NO}_{3}{ }^{-}$leaching from urea applied with urease and nitrification inhibitors to a maize (Zea mays) crop', Agric. Ecosyst Environ., vol. 149, pp. 64-73, 2012, doi:10.1016/j.agee.2011.12.016

[2] H.T.B. Thao, T. George, T. Yamakawa, and L.R. Widowati, 'Effects of soil aggregate size on phosphorus extractability and uptake by rice (Oryza sativa L.) and corn (Zea mays L.) in two Ultisols from the Philippines', Soil Sci. Plant
Nutr., vol. 54, pp. 148-158, 2008, doi: 10.1111/j.1747- 0765.2007.00220.x.

[3] M. Wang, Q. Zheng, Q. Shen, and S. Guo, 'The critical role of potassium in plant stress response', Intern. J. Molec. Sci., vol. 14, pp. 7370-7390, 2013.

[4] L. Chen , W.B. Xun, L. Sun, N. Zhang , Q.R. Shen, and R.F. Zhang, 'Effect of different longterm fertilization regimes on the viral community in an agricultural soil of southern China', Eur. Soil Biol., vol. 62, pp. 121-126, 2014, doi: 10.1016/j.ejsobi.2014.03.006.

[5] E. Oleńska, W. Małek, M. Wójcik, I. Swiecicka, S. Thijs, and J. Vangronsveld, 'Beneficial features of plant growth-promoting rhizobacteria for improving plant growth and health in challenging conditions: A methodical review', Sci. Total Environ., 2020, doi: 10.1016/j.scitotenv.2020.140682

[6] R. Backer, J. S. Rokem, G. Ilangumaran, L. Lamont, D. Praslickova, E. Ricci, S. Subramanian, and D.L. Smith, 'Plant growth-promoting rhizobacteria: context, mechanisms of action, and roadmap to commercialization of biostimulants for sustainable agriculture', Front.Plant Sci., vol. 9 pp. 1473, 2018, doi: 10.3389/fpls.2018.01473.

[7] K. Mahmud, S. Makaju, R. Ibrahim, and A. Missaoui, 'Current progress in nitrogen fixing plants and microbiome research', Plants, vol. 9, pp. 97, 2020, doi: 10.3390/plants9010097.

[8] W.B. McGill and C.V. Cole, 'Comparative aspects of cycling of organic C, N, S and P through soil organic matter', Geoderma, vol. 26, pp. 267-268, 1986, doi:10.1016/0016-7061(81)90024-0.

[9] N.S. Subba-Rao, 'Soil Microorganisms and Plant Growth’, SCIENCE PUB INC., New Delhi, 1995.

[10] T. Patel and M. Saraf, 'Biosynthesis of phytohormones from novel rhizobacterial isolates and their in vitro plant growth-promoting efficacy', J. Plant Int., vol. 12, pp. 480 -487, 2017, doi: 10.1080/17429145.2017.1392625.

[11] H. Rodríguez and R. Fraga, 'Phosphate solubilizing bacteria and their role in plant growth promotion', Biotechnol. Adv., vol. 17, pp. 319 339, 1999, doi: 10.1016/S0734 -9750(99)00014 2. 
[12] M.A. Ali, M.M. Ajaz, M. Rizwan, M.F. Qayyum, M. Arshad, S. Hussain, N. Ahmad, and M.A. Qureshi, 'Effect of biochar and phosphate solubilizing bacteria on growth and phosphorus uptake by maize in an Aridisol', Arabian $J$. Geosci., vol. 13, pp. 1-9, 2020, doi:: 10.1007/s12517-020-05326-6

[13] R.L. Isbelia, R.R. Bernier, P. Simard, G. Tanguay, and H. Antoun, 'Characteristics of phosphate solubilization by an isolate of a tropical Penicillium rugulosum and two UV induced mutants', FEMS Microbiol. Ecol., vol. 28, pp. 291-295, 1999.

[14] B. Gizaw, Z. Tsegay, G. Tefera, E. Aynalem, M. Wassie, and E. Abatneh, 'Phosphate solubilizing fungi isolated and characterized from teff rhizosphere soil collected from north Showa and Gojam, Ethiopia', J. Fert. Pest., vol. 8, pp. 1-9, 2017.

[15] M.A. Whitelaw, J.T. Harden, and R.T. Helyar, 'Phosphate solubilization in solution culture by the soil fungus Penicillum radicum', Soil Biol. Biochem., vol. 31, pp. 655-665, 1999.

[16] S. Desai, 'Eighteen microbial inoculants for enhanced nutrient uptake and quality of crops', In: K.S. Shankar, R.N. Kumar, Pushpanjali, K. Nagasree, G. Nirmala, and N. S. Raju, (Eds.), 'Reshaping Agriculture and Nutrition Linkages for Food and Nutrition Security, ICAR-Central Research Institute For Dryland Agriculture, Hyderabad, 2016.

[17] D. Egamberdieva, S.J. Wirth, A.A. Alqarawi,E.F. Abd Allah, and A. Hashem, 'Phytohormones and beneficial microbes: essential components for plants to balance stress and fitness', Front Microbiol., vol. 8, pp. 2104, 2017, doi: 10.3389/fmicb.2017.02104

[18] C.L. Patten, and R.R Glick, 'Bacterial biosynthesis of indole - 3 -acetic acid', Can. J. Microbiol., vol. 42, pp. 207 -220, 1996, doi:10.1139/m96 -032.

[19] S.H. Park, M. Elhiti, H. Wang, A. Xu, D. Brown, and A. Wang, 'Adventitious root formation of in vitro peach shoots is regulated by auxin and ethylene', Scientia Horticulturae, vol. 226, pp. 250-260, 2017, doi: 10.1016/j.scienta.2017.08.053.

[20] D. Rivera, V. Mora, G. Lopez, S. Rosas, S. Spaepen, J. Vanderleyden, and F. Cassan, 'New insights into indole-3-acetic acid metabolism in Azospirillum brasilense', J. Appl. Microbiol., vol. 125, pp. 1774-1785, 2018
[21] S. Horemans, and K. Vlassak, 'Production of indol-3-acetic acid by Azospirillum brasilense', In: W. Klingmuller (Ed.), Azospirillum III: Genetics, Physiology, Ecology. SPRINGER-VERLAG, Berlin, 1985.

[22] A. Karnwal, 'Production of Indol acetic acid by Pseudomonas fluorescent in the presence of Ltryptophan and rice root exudates', J.Plant Pathol., vol. 91, pp. 61-63, 2009

[23] A.M. Restu, and R.Y. Payangan, 'Production of IAA (Indole Acetic Acid) of the rhizosphere fungus in the Suren community forest stand', IOP Conf. Ser.: Earth Environ. Sci., vol. 343, no. 1, pp. 012058, 2019

[24] Z. Tsegaye, F. Assefa, G. Tefera, T. Alemu, and B. Gizaw, 'Characterization and Identifi cation of Tef (Eragrostis tef) seed endophytic bacterial species and evaluate their effect on plant growth promotion', J. Plant Pathol. Microbiol., vol. 9, pp. 438-446, 2018

[25] R. Mehrotra, and K. Aneja, 'An introduction to mycology’, NEW AGE INTERNATIONAL, 1990.

[26] M. Chaiharn, and S. Lumyong, 'Screening and optimization of indole-3-acetic acid production and phosphate solubilization from rhizobacteria aimed at improving plant growth', Curr. Microbiol., vol. 62, pp.173-181, 2011.

[27] R.E. Pikovskaya, 'Mobilization of phosphorus in soil in concentration with vital activity of some microbial species', Microbiologiya, vol. 17, pp. 362-377, 1948

[28] M.E. Premono, A. M. Moawad, and P.L.G.Vlek, 'Effect of phosphate-solubilizing Pseudomonas putida on the growth of maize and its survival in the rhizosphere', Indonesian J. Crop Sci., vol. 11, pp. 13-23, 1996.

[29] J.M. Bric, R.M. Bostock, and S.E. Silverstone, 'Rapid in situ assay for indoleacetic acid production by bacteria immobilized on a nitrocellulose membrane', Appl. Environ. Microbiol., vol. 57, pp. 535-538, 1991.

[30] S.A. Gordon, and R. P. Weber, 'Colorimetric estimation of indoleacetic acid', Plant Physiol., vol. 26, pp. 192-195, 1951.

[31] M.J.S. Ruegger, and S.M. Tauk-Tornisielo, 'Cellulase activity of fungi isolated from soil of the Ecological Station of Jureia- Itatins, Sao Paulo, Brazil', Brazilian J. Bot., vol. 27, pp. 205211, 2004. 
[32] Ten, L. N., W. T. Im, M. K. Kim, M. S. Kang, S. and $\mathrm{T}$. Lee, 'Development of a plate technique for screening of polysaccharide-degrading microorganisms by using a mixture of insoluble chromogenic substrates', J. Microbiol. Meth., vol. 56, pp. 375-382, 2004.

[33] P. Beguin P, and J.P. Aubert, 'The biological degradation of cellulose', FEMS Microbiol. Rev., vol. 13, pp. 25- 58, 1994.

[34] M. Laranjo, J. Machado, J.P. Young, and S. Oliveira, 'High diversity of chickpea Mesorhizobium species isolated in a Portuguese agricultural region', FEMS Microbiol. Ecol., vol. 48, pp. 101-107, 2004, doi: 10.1016/j.femsec.2003.12.015.

[35] L. Xu, Y. Zhang, L. Wang, W. Chen, and G. Wei, 'Diversity of endophytic bacteria associated with nodules of two indigenous legumes at different altitudes of the Qilian Mountains in China', Syst. Appl. Microbiol., vol. 37, pp. 457-465., 2014, doi:10.1016/j.syapm.2014.05.009.

[36] A. Zaheer, B.S. Mirza, J.E. Mclean, S. Yasmin, T.M. Shah, K.A. Malik, and M.S. Mirza, 'Association of plant growth-promoting Serratia spp. with the root nodules of chickpea', Res. Microbiol., vol. 167, pp. 510-520, 2016, doi: 10.1016/j.resmic.2016.04.001

[37] H. Fankem, D. Nwaga, A. Deubel, L. Dieng, W. Merbach, and F.X. Etoa, 'Occurrence and functioning of phosphate solubilizing microorganisms from oil palm tree (Elaeis guineensis) rhizosphere in Cameroon', Afr. J. Biotechnol., vol. 5, pp. 2450-2460, 2006, doi: 10.1186/1471-2164-7-318.

[38] S.H. Habib, H. Kausar, H.M. Saud, M.R. Ismail, and R. Othman, 'Molecular characterization of stress tolerant plant growth promoting rhizobacteria (PGPR) for growth enhancement of rice', Int. J. Agric. Biol., vol. 18, pp. 184-191, 2015 .

[39] J. Yadav, J. P. Verma, and K. N. Tiwari, 'Plant growth promoting activities of fungi and their effect on chickpea plant growth', Asian J. Biol. Sci., vol. 4, pp. 291-299, 2011.

[40] M. Iman, 'Effect of phosphate solubilizing fungi on growth and nutrient uptake of soyabean (Glycine max L.) plants', J. Appl. Sci. Res., vol. 4, pp. 592-598, 2008.

[41] S.V. Mahamuni, P. V. Wani, and A. S. Patil, 'Isolation of phosphate solubilizing fungi from rhizosphere of sugarcane \& sugar beet using TCP
\& RP solubilization', Asian J. Biomed. Pharm. Sci., vol. 2, pp. 237-244, 2012.

[42] S. Alam, S. Khalil, A. Najma, and M. Rashid, 'In vitro solubilization of inorganic phosphate by phosphate solubilizing microorganisms (PSM) from maize rhizosphere', Int. J. Agric. Biol., vol.4 pp. 454-458, 2002.

[43] K. Prajapati, M.C. Sharma, and H.A. Modi, 'Isolation of two potassium solubilizing fungi from ceramic industry soils', Life Sci. Leafl., vol. 5, pp. 71-75, 2012.

[44] I. Bahadur, V.S. Meena, and S. Kumar, 'Importance and application of potassic biofertilizer in Indian agriculture', Int. Res. J. Biol. Sci., vol. 3, pp. 80-85, 2014.

[45] D. Bhardwaj, M.W. Ansari , R.K. Sahoo, and N. Tuteja, 'Biofertilizers function as key player in sustainable agriculture by improving soil fertility, plant tolerance and crop productivity', Microb. Cell Fact., vol. 13, pp. 66, 2014.

[46] M. Ahmad, S.M. Nadeem, M. Naveed, and Z.A. Zahir, 'Potassium-solubilizing bacteria and their application in agriculture', In: Meena, V.S., B.R. Maurya, J.P. Verma, and R.S. Meena, (Eds.), 'Potassium solubilizing microorganisms for sustainable agriculture', SPRINGER INDIA, New Delhi, 2016.

[47] E. Bakhshandeh, H. Pirdashti, and K.S. Lendeh, Phosphate and potassium-solubilizing bacteria effect on the growth of rice', Ecol. Eng., vol. 103, pp. 164-169, 2017.

[48] C.L. Pattern, and B.R. Glick, 'Role of Pseudomanas putida indo lactic acid in development of the host plant root system', App. Eniron. Microbiol., vol. 68, pp. 3795-3801, 2002.

[49] M.R. Swain, S.K. Naskar, and R.C. Ray, 'Indole 3 -acetic acid production and effect on sprouting of yam. (Dioscorea rotundata $\mathrm{L}$ ) Minisetts by Bacillus subtilis Isolated from culturable cowdung microflora', Polish J.Microbiol., vol. 56, pp. 103-110, 2007.

[50] S. Mutluru, and V.M. Konada, 'Bioproduction of indole acetic acid by Rhizobium strains isolated from root nodules of green manure crop, Sesbania sesban(L.) Merr', Iranian J. Biotechnol., vol. 5 , pp. 178-182, 2007.

[51] T. Kosuge, and M. Sanger, 'Indole acetic acid, its synthesis and regulation: basis for tumorigen city in plant disease', Recent Adv. Phytochem., vol. 20, pp. 147-161, 1987. 
[52] T. Oberhansli, G. Defago, and D. Haas, 'Indole-3acetic acid (IAA) synthesis in the biocontrol strain CHAO of Pseudomonas fluoresces: role of tryptophan side chain oxidase', J. Gen Microbiol., vol. 137, pp. 2273-2279, 1991.

[53] D. Kluepfel, 'Screening of prokaryotes for cellulose and hemicellulose-degrading enzymes', Meth. Enzymol., vol. 160, pp. 180-186, 1988.

[54] H.H. Azzaz, H.A. Murad, A.M. Kholif, M.A. Hanfy, and M.H. Abdel Gawad, 'Optimization of culture conditions affecting fungal cellulose production', Res. J. Microbiol., vol. 7, pp. 23-31, 2012.

[55] R. Sharada, G. Venkateswarlu, S. Venkateshwar, and M.A. Rao, 'Production of cellulase-A review', Int. J. Pharm. Chem. Biol. Sci., vol. 3, 2013.

[56] P. Saravanan, R. Muthuvelayudham, T. and Viruthagiri, 'Enhanced production of cellulase from pineapple waste by response surface methodology', J. Engineer., vol. 2013, 2013.
[57] R. Meneses, G. Varela, and H. Flores, 'Evaluating the use of Atriplex nummularia hay on feed intake, growth, and carcass characteristics of creole kids', Chilean J. Agric. Res., vol. 72, pp. 74-79, 2012.

[58] G.H. Emert, E.K. Gum, J.A. Lang, T.H. Lin, and R.D. Brown, 'Cellulases', p. 79-100. In: Food Related Enzymes (J. Whitaker, ed.), Advances in Chemistry Series No. 136, AMERICAN CHEMICAL SOCIETY, Washington, D.C., 1974.

[59] L. N. Ten, W. T. Im, M. K. Kim, M. S. Kang, and S. T. Lee, 'Development of a plate technique for screening of polysaccharide-degrading microorganisms by using a mixture of insoluble chromogenic substrates', J. Microbiol. Meth., vol. 56, pp. 375-382, 2004.

[60] M.J.S. Ruegger, and S.M. Tauk-Tornisielo, 'Cellulase activity of fungi isolated from soil of the Ecological Station of Jureia-Itatins, Sao Paulo, Brazil', Brazilian J. Bot., vol. 27, pp. 205-211, 2004. 